\title{
Non-Convulsive Status Epilepticus in Ischemic Stroke and its Impact on Prognosis
}

\author{
Nabil Kitchener ${ }^{1 *}$, Hany Zakieldine ${ }^{2}$, Romany Adly ${ }^{1}$, Mohamed Helmy ${ }^{1}$, and Sadek Helmy ${ }^{3}$ \\ ${ }^{1}$ Department of Neuropsychiatry, El-Mataryia Teaching Hospital, Egypt \\ ${ }^{2}$ Department of Neuropsychiatry, Ain Shams University, Egypt \\ ${ }^{3}$ Department of Neuropsychiatry, Cairo University, Egypt
}

*Corresponding author: Nabil Kitchener, Department of Neuropsychiatry, ElMataryia Teaching Hospital, General Organization for Teaching Hospitals and Institutes, Egypt.

Received Date: August 27, 2018

Published Date: September 24, 2018

\section{Abstract}

Background: Emerging data support a higher than previously thought incidence of Non-Convulsive Epileptic Activity in Ischemic Stroke Patients, which is an important consideration affecting prognosis.

Objectives: to determine frequency of non-convulsive status epilepticus (NCSE), in the form of continuous electrographic Seizures with no motor manifestations, in ischemic stroke patients and how it affects outcome.

Methods: We prospectively and consecutively studied 3168 patients with acute stroke, collected from January 2006 to December 2009. DEEG was done for every stroke patient within 24 hours of admission to ICU and repeated if his level of consciousness changed. We determined initial stroke severity, mortality, and outcome in survivors. Stroke severity was assessed, clinically and by imaging. Multiple logistic and linear regression outcome analyses included age, gender, stroke severity, atrial fibrillation, ischemic heart disease, blood glucose level, claudication, and hypertension.

Results: NCSE were detected in 197 (6.2\%) patients in the first EEG. With second EEG done after change in level of consciousness of 1054 patients, total number of patients showed NCSE increased to 579 (18.27 \%). Patients with early NCSE Mortality rate is higher than that of late NCSE, Mortality rate is higher in patients with disturbed level of consciousness and no NCSE, than those with NCSE. ICU stay duration is shorter and clinical outcome is better for patients with disturbed level of consciousness and NCSE.

Conclusion: NCSE is a frequent finding in acute stroke, reaching 18\%, Patients with stroke would benefit from an EEG. Early NCSE increase Mortality rate. Treating NCSE improves outcome.

\section{Introduction}

Non-convulsive Status Epilepticus (NCSE) is an under reported, treatable cause of coma and has variety of clinical and EEG presentations. It is defined as a mental status with changes from base line of at least 30 - 60 minutes duration associated with continuous or near continuous ictal discharges on EEG [1].

Stroke is known to be a common risk factor for status epilepticus (SE) in adults [2,3] and has been reported in $22-32 \%$ of cases in different studies $[4,5]$. Recent studies have found slightly higher rates such as $14-27 \%$ in patients with cerebrovascular disease [68] and $17 \%$ in patients with intracerebral hemorrhage [9].

Nonconvulsive Status Epilepticus (NCSE) was originally described in patients with chronic epilepsy, but it's now recognized with increased frequency in other patient populations, especially the critically ill. The International League Against Epilepsy (ILAE) defines status epilepticus as a condition resulting either from the failure of the mechanisms responsible for seizure termination or from the initiation of mechanisms that lead to abnormally prolonged seizures [10].

Nonconvulsive status epilepticus is surprisingly common, occurring in $8-10 \%$ of comatose patients in intensive care units $[1,11]$ and in $37 \%$ of patients with unexplained alteration of consciousness [12]. Other studies showed that in the Neurologic Intensive Care Unit, up to $34 \%$ of patients undergoing EEG monitoring have nonconvulsive seizures (NCS), and 76\% of these cases are nonconvulsive SE [13]. Even after excluding all patients 
with any clinical evidence or history of seizures, still $8 \%$ of comatose patients have NCS. [1] NCS have been described in $27 \%$ of patients with altered consciousness, [12] 48\% of patients after the termination of generalized convulsive SE, [10] 22\% with severe traumatic brain injury (TBI), [14] 6\% with ischemic stroke, [15] and $28 \%$ with intracerebral hemorrhage (ICH) [15].

Nonconvulsive SE can be diagnosed definitively only by electroencephalogram (EEG). In patients with baseline coma or encephalopathy, NCSE typically includes patients with more than 30 total minutes of ictal electroencephalogram (EEG) activity in any given hour of recording (ie, $>50$ percent of the record) $[10,16]$.

It is a treatable neurologic condition, associated with an altered mental state. NCSE is associated with high morbidity and mortality thus warranting a rapid diagnosis and treatment [4,15-18].

Emerging data supports a higher than previously thought incidence of Non-Convulsive Epileptic Activity in Ischemic Stroke Patients, which is an important consideration affecting prognosis $[6,7,8,15,16]$

Table 1: Primary data of study patients' group.

\begin{tabular}{|c|c|c|c|}
\hline & Total & Female & $65.4 \pm 14.7$ \\
\hline Age & $63.2 \pm 11.8$ & $61.2 \pm 9.3$ & $1457(46 \%)$ \\
\hline Sex, FM & 3168 & $1711(54 \%)$ & $961(57 \%)$ \\
\hline Hypertension & Risk Factors & $128(33 \%)$ \\
\hline AF & $1686(53.20 \%)$ & $725(43 \%)$ & $223(37.1 \%)$ \\
\hline IHD & $389(12.27 \%)$ & $261(67 \%)$ & $350(46.1)$ \\
\hline High Blood glucose Level & $602(19 \%)$ & $379(62.9 \%)$ & $388(42 \%)$ \\
\hline Hypercholestrolemia & $760(23.90 \%)$ & $410(53.9)$ & $926(77 \%)$ \\
\hline Current Smokers & $924(29.1 \%)$ & $536(58 \%)$ & $313(43 \%)$ \\
\hline Previous Stroke/TIAs & $1204(38 \%)$ & $278(23 \%)$ & $105(42 \%)$ \\
\hline Claudication & $728(22.9 \%)$ & $415(57 \%)$ & 0 \\
\hline OCP consumption in females & $250(7.89 \%)$ & $446(26 \%)$ & \\
\hline Level of Consciousness =Alert on Admission & $446(14 \%)$ & & 1417 \\
\hline$(85.9)$ & 2724 & & \\
\hline$(52.1 \%)$ & $1307(47.9)$ & & \\
\hline
\end{tabular}

\section{Results}

NCSE were detected in 197 (6.2\%) patients in the first EEG. Second EEG was done for1054 patients after change in their level of consciousness, the total number of patients showed NCSE EEG changes increased to 579 (18.27\%) (Table 2). Mortality rate was

\section{Objectives}

To determine frequency of non-convulsive status epilepticus (NCSE), in the form of continuous electrographic Seizures with no motor manifestations, in ischemic stroke patients and how it affects outcome.

\section{Methods}

We prospectively and consecutively studied 3168 patients with acute stroke, admitted to Coptic Specialized Hospital, and Mataryia Teaching Hospital, General Organization for Teaching Hospitals and Institutes, collected from January 2006 to December 2009. DEEG was done for every stroke patient within 24 hours of admission to ICU and repeated if his level of consciousness changed.

We determined initial stroke severity, mortality, and outcome in survivors, using National Institutes of Health Stroke Scale Score (NIHSS) and Modified Rankin Score (mRS) [19,20,21]. Stroke severity was assessed, clinically and by imaging. Multiple logistic and linear regression outcome analysis included age, gender, stroke severity, atrial fibrillation, ischemic heart disease, blood glucose level, claudication, and hypertension Table 1.

Table 2: Frequency of NCSE in acute stroke patients, proved by 1st EEG and 2nd EEG.

\begin{tabular}{|c|c|c|c|}
\hline & Number of Patients & Percentage & $100 \%$ \\
\hline Total & 3168 & 6.2 & $33.27 \%$ \\
\hline NCSE by First EEG & 197 & $12 \%$ of total & $\begin{array}{c}36.2 \% \text { of patients with Deteriorated } \\
\text { LOC }\end{array}$ \\
\hline NCSE by Second EEG & 1054 & 18.27 & \\
\hline
\end{tabular}


Table 3: shows Initial stroke severity and outcome in survivors.

\begin{tabular}{|c|c|c|}
\hline Stroke Severity & On Admission & On Discharge \\
\hline Modified Rankin Score (mRS) & $3.5 \pm 1.06$ & $2.2 \pm 1.9$ \\
\hline National Institutes of HealthStroke Scale Score (NIHSS) & $7.4 \pm 4.9$ & $5.6 \pm 5.3$ \\
\hline
\end{tabular}

Table 4: Follow-up data of study patients' group.

\begin{tabular}{|c|c|c|c|c|c|c|}
\hline & Total & $\begin{array}{c}\text { Alert on } \\
\text { Admission }\end{array}$ & $\begin{array}{c}\text { Disturbed LOC } \\
\text { on Admission } \\
\text { without NCSE }\end{array}$ & $\begin{array}{c}\text { Disturbed LOC on } \\
\text { Admission with } \\
\text { NCSE }\end{array}$ & $\begin{array}{c}\text { Delayed } \\
\text { disturbed LOC } \\
\text { with NCSE }\end{array}$ & $\begin{array}{c}\text { Delayed } \\
\text { disturbed LOC } \\
\text { without NCSE }\end{array}$ \\
\hline & 3168 & 2724 & 247 & 197 & 382 & 672 \\
\hline $\begin{array}{c}\text { In hospital } \\
\text { Mortality rate }\end{array}$ & $398(12.50 \%)$ & & $33 \mathrm{a}^{* *}(13.4 \%)$ & $32 \mathrm{a}^{* *}(16.2 \%)$ & $49 \mathrm{a}^{* *}, \mathrm{~b}^{* *}(12.8 \%)$ & $123 \mathrm{a}^{* *}, \mathrm{~b}^{* *}(18.3 \%)$ \\
\hline ICU stay duration & $7 \pm 3.2$ & $9.2 \pm 3.2$ & $8.8 \pm 3.6^{*}$ & $8.2 \pm 1.3^{*}$ & $9.6 \pm 2.1^{*}$ \\
\hline $\begin{array}{c}\text { Clinical outcomeby } \\
\text { mRS }\end{array}$ & $2.2 \pm 1.9$ & & $2.4 \pm 1.3^{*}$ & $2.1 \pm 1.1^{*}$ & $3.1 \pm 1.8^{*}$ \\
\hline
\end{tabular}

Clinical outcome is better for patients with disturbed level of consciousness and NCSE (Table 4).

\section{Clinical outcome in survivors}

Regression outcome analysis included age, gender, stroke severity, atrial fibrillation, ischemic heart disease, blood glucose level, claudication, and hypertension. Results showed that gender, ischemic heart disease and peripheral arterial disease does not correlate with clinical outcome in survivors in this study (Table 5). Stroke severity has a great impact on clinical outcome of all study groups, age and atrial fibrillation has been correlated with bad prognosis in sector of patients without NCSE. Diabetes correlates with less favorable clinical outcome in unconscious patients without NCSE. Also, in unconscious patients without NCSE, and group of patients who proved to suffer from NCSE on first EEG, hypertension was correlated with less favorable clinical outcome (Table 5).

Table 5: Regression coefficients (B) and standard errors (SEs) showing relation between outcome in survivals and many variables (Z-scores)

\begin{tabular}{|c|c|c|c|c|}
\hline Survivors Variable & With Early NCSE & With Late NCSE & Conscious without NCSE & Non-Conscious without NCSE \\
\hline Age & 0.031 & 0.0189 & $-0.106(0.103)^{*}$ & $-0.102(0.104)^{*}$ \\
\hline Gender & 0.024 & 0.013 & 0.051 & 0.041 \\
\hline Stroke Severity & $-0.118(-0.102)^{*}$ & $-0.120(0.109)^{*}$ & $-0.108(-0.104)^{*}$ & $-0.115(-0.120)^{*}$ \\
\hline $\mathrm{AF}$ & 0.033 & 0.018 & $-0.115(-0.106)^{*}$ & $-0.108(-0.104)^{*}$ \\
\hline IHD & 0.053 & 0.028 & 0.032 & 0.041 \\
\hline Diabetes & 0.028 & 0.034 & 0.046 & $-0.103(-0.104)^{*}$ \\
\hline Claudication & 0.036 & 0.018 & 0.027 & 0.039 \\
\hline Hypertension & $-0.105(-0.102)^{*}$ & 0.022 & 0.046 & $-0.109(-0.109)^{*}$ \\
\hline
\end{tabular}

${ }^{*} B(S E)$ Statistically significant $(p<0.01)$.

\section{Discussion}

Non-Convulsive Seizure activities are not uncommon in critically ill patients in NICU and were recorded in $34 \%$ of patients undergoing cEEG in NICU [12,13] and in 37\% of comatose patients without signs of seizure activity [18]. In the Columbia study seizures were detected in $19 \%$ of patients who had cEEG monitoring; the seizures were exclusively Non-Convulsive in $92 \%$ of patients [19]. The main clinical signs of NCSE include altered level of consciousness and abnormal eye movements which mandate urgent EEG. Severely impaired mental state, and ocular movement abnormalities were seen significantly more often in the NCSE [22]. In our study, Non-Convulsive Seizure activities were recorded from $6.2 \%$ of total study population, 3168 stroke patients, by the first EEG done with 24 hours of admission to hospital, the percentage rise to 18.27 on second recording, which seems to be less frequent than mentioned in literature. If fully conscious patients were excluded from the calculations, percentage will rise to $36.2 \%$; which is going with previous studies run by Jordan [13], Privitera [23] and Claassen [24].
NCS in the acute stroke setting further increase neuronal injury, due to excito-toxicity and increased glutamate release, and hence morbidity. Deterioration of level of consciousness occurred in more than one third of our study group, and $36.2 \%$ of them proved to suffer NCSE. Results showed that stroke severity has a great impact on clinical outcome of all study groups, age and atrial fibrillation has been correlated with bad prognosis in sector of patients without NCSE, as that point to existence of a continuous source of emboli. Also, in unconscious patients without NCSE, and group of patients who proved to suffer from NCSE on first EEG, hypertension was correlated with less favorable clinical outcome, as encephalopathic pattern showed on first EEG indicated severe derangement of brain physiology.

NCSE is a treatable neurologic condition, associated with an altered mental state, when it occurs in situation of acute stroke as a change from baseline, its proper management using proper antiepileptic medications and steroid if needed, carries a favorable outcome. Therefore, patients with severe stroke would benefit from an EEG in any case of unexplained changes in consciousness. 
Moreover, patients having a history of severe ischemic stroke should be thoroughly investigated if consciousness or behavior suddenly changes in order not to miss a NCS [25].

\section{Conclusion}

NCSE seems to be an important issue in stroke; NCSE is a frequent finding reaching 18\% in current study, thus requiring a high degree of suspicion in an acute stroke setting to avoid further neuronal injury and morbidity. Patients with stroke would benefit from an EEG. Early NCSE increase Mortality rate. Treating NCSE improves outcome. The potential associations of NCSE with certain stroke localizations may require further prospective studies.

\section{Acknowledgement}

None

\section{Conflict of Interest}

No conflict of interest.

\section{References}

1. Towne AR, Waterhouse EJ, Boggs JG, Garnett LK, Brown AJ, et al. (2000) Prevalence of nonconvulsive status epilepticus in comatose patients. Neurology 54(2): 340-345.

2. DeLorenzo RJ, Hauser WA, Towne AR, Boggs JG, Pellock JM, et al. (1996) A prospective, population-based epidemiologic study of status epilepticus in Richmond, Virginia. Neurology 46(4): 1029-1035.

3. Fountain NB (2000) Status epilepticus: risk factors and complications. Epilepsia 41 (Suppl 2): S23-S30.

4. Towne AR, Pellock J M, Ko D, DeLorenzo RJ (1994) Determinants of mortality in status epilepticus. Epilepsia 35(1): 27-34.

5. Scholtes FB, Renier WO, Meinardi H (1994) Generalized convulsive status epilepticus: causes, therapy, and outcome in 346 patients. Epilepsia 35(5): 1104-1112.

6. Milandre L, Broca P, Sambuc R, Khalil R (1992) Les crises epileptiques au cours et au décours des accidents cerebrovasculaires: analyse clinique de 78 cases [in French]. Reviews in Neurology 148: 767-772.

7. Rumbach L, Sablot D, Berger E, Tatu L, Vuillier F, Moulin T (2000) Status epilepticus in stroke. Report on a hospital-based stroke cohort. Neurology 54(2): 350-354.

8. Labovitz DL, Hauser WA, Sacco RL (2001) Prevalence and predictors of early seizure and status epilepticus after first stroke. Neurology 2001; 57(2): 200-206.

9. Sung CY, Chu NS (1989) Epileptic seizures in intracerebral hemorrhage. Journal of Neurology, Neurosurgery and Psychiatry 52(11): 1273-1276.

10. Trinka E, Cock H, Hesdorffer D, Rossetti AO, Scheffer IE, et al. (2015) A definition and classification of status epilepticus--Report of the ILAE
Task Force on Classification of Status Epilepticus. Epilepsia 56(10):15151523.

11. Kapadia FN, Vadi S, Shukla U, Gursahani R (2005) Utility of electroencephalogram in altered states of consciousness in intensive care unit patients. Indian J Crit Care Med 9(1):19-21.

12. Privitera M, Hoffman M, Moore JL, Jester D (1994) EEG detection of nontonic-clonic status epilepticus in patients with altered consciousness. Epilepsy Res 18(2): 155-166.

13. Jordan KG (1992) Nonconvulsive seizures (NCS) and nonconvulsive status epilepticus (NCSE) detected by continuous EEG monitoring in the neuro ICU. Neurology 42:180.

14. Vespa PM, Nuwer MR, Nenov V, Ronne-Engstrom E, Hovda DA, et al. (1999) Increased incidence and impact of nonconvulsive and convulsive seizures after traumatic brain injury as detected by continuous electroencephalographic monitoring. J Neurosurg 91(5): 750-756.

15. Vespa PM, O'Phelan K, Shah M, Mirabelli J, Starkman S, et al. (2003) Acute seizures after intracerebral hemorrhage: a factor in progressive midline shift and outcome. Neurology 60:1441-1446.

16. Brophy GM, Bell R, Claassen J, Alldredge B, Bleck TP, et al. (2012) Guidelines for the evaluation and management of status epilepticus. Neurocrit Care 17(1): 3-23.

17. Ruegg SJ, Dichter MA (2003) Diagnosis and treatment of NonConvulsive Status Epilepticus in an ICU setting. Curr Treat Options Neurol 5(2): 93110.

18. Kaplan PW (1999) Assessing the outcomes in patients with nonconvulsive status epilepticus: Non convulsive status epilepticus is an under diagnosed, potentially over treated, and confounded by comorbidity. J Clinic Neurophysiol 16(4): 341-352.

19. Lyden PD, Lu M, Levine SR, Brott TG, Broderick J (2001) A modified national institutes of health stroke scale for use in stroke clinical trials preliminary reliability and validity. Stroke 32(6): 1310-1316.

20. Rankin J (1957) Cerebral vascular accidents in patients over the age of 60. II. Prognosis. Scott Med J 2(5): 200-215.

21. Bonita R, Beaglehole R (1988) Modification of Rankin Scale: Recovery of motor function after stroke. Stroke 19(12):1497-1500.

22. Husain AM, Horn GJ, Jacobson MP (2003) Non-convulsive status epilepticus: usefulness of clinical features in selecting patients for urgent EEG. J Neurol Neurosurg Psychiatry 74(2): 189-191.

23. Privitera MD, Strawsurg RH (1994) Electroencephalographic monitoring in the emergency department. Emerg Med Clinics North Am 12(4): 1089-1100.

24. Claassen J, Mayer SA, Kowalski RG, Emerson RG, Hirsch LJ (2004) Detection of electrographic seizures with continuous EEG monitoring in critically ill patients. Neurology 62(10): 1743-1748.

25. DeLorenzo RJ, Waterhouse EJ, Towne AR, Boggs JG, Ko D, et al. (1998) Persistent nonconvulsive status epilepticus after the control of convulsive status epilepticus. Epilepsia 39(8): 833-840. 